\title{
Primary thyroid angiosarcoma in a non-endemic region - a rare case
}

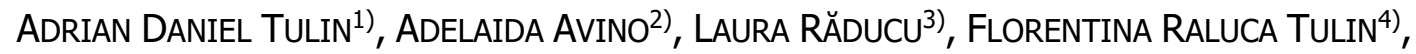 \\ OVIDIU ŞTIRU ${ }^{5)}$, ANDRA-ELENA BALCANGIU-STROESCU6), DELIA TIMOFTE ${ }^{7)}$, MARIA DANIELA TĂNĂSESCU ${ }^{8)}$, \\ DANIELA-GABRIELA BĂLAN ${ }^{9)}$, CRISTIAN-RADU JECAN ${ }^{3)}$, DORIN IONESCU ${ }^{8)}$ \\ 1) Department of Anatomy, Faculty of Medicine, Carol Davila University of Medicine and Pharmacy, Bucharest, Romania; \\ Department of General Surgery, Prof. Dr. Agrippa Ionescu Clinical Emergency Hospital, Bucharest, Romania \\ 2) Department of Plastic and Reconstructive Surgery, Prof. Dr. Agrippa Ionescu Clinical Emergency Hospital, Bucharest, Romania \\ 3) Department of Plastic and Reconstructive Surgery, Faculty of Medicine, Carol Davila University of Medicine and Pharmacy, \\ Bucharest, Romania; Department of Plastic and Reconstructive Surgery, Prof. Dr. Agrippa Ionescu Clinical Emergency Hospital, \\ Bucharest, Romania \\ 4) Department of Embryology, Faculty of Medicine, Carol Davila University of Medicine and Pharmacy, Bucharest, Romania; \\ Department of Endocrinology, Prof. Dr. Agrippa Ionescu Clinical Emergency Hospital, Bucharest, Romania \\ 5) Department of Cardiovascular Surgery, Faculty of Medicine, Carol Davila University of Medicine and Pharmacy, Bucharest, \\ Romania; Department of Cardiovascular Surgery, Prof. Dr. C. C. Iliescu Emergency Institute for Cardiovascular Diseases, \\ Bucharest, Romania \\ 6) Discipline of Physiology, Faculty of Dental Medicine, Carol Davila University of Medicine and Pharmacy, Bucharest, Romania; \\ Department of Dialysis, Emergency University Hospital Bucharest, Romania \\ 7) Department of Dialysis, Emergency University Hospital Bucharest, Romania \\ 8) Discipline of Internal Medicine I and Nephrology, Department of Medical Semiology, Faculty of Medicine, Carol Davila \\ University of Medicine and Pharmacy, Bucharest, Romania; Department of Nephrology, Emergency University Hospital \\ Bucharest, Romania \\ 9) Discipline of Physiology, Faculty of Dental Medicine, Carol Davila University of Medicine and Pharmacy, Bucharest, Romania
}

\begin{abstract}
Thyroid angiosarcoma (AS) is a specific type of vascular tumor that arises from the endothelial cells, being highly aggressive, with increased recurrence rates and metastasis. It is characterized by positive endothelial markers and co-positive markers for cytokeratins and epithelial membrane antigen. We are describing the case of a 76-year-old patient who presented to the hospital for dyspnea and asthenia. The clinical and paraclinical investigations confirmed the presence of a right large thyroid nodule, which turned out positive at immunostaining for AS. Even if thyroid AS is a rare type of tumor, mainly described in the Alps, one has to take into account that it can evolve in any other regions and should be considered as a differential diagnosis.
\end{abstract}

Keywords: thyroid, angiosarcoma, epithelioid.

\section{a Introduction}

Thyroid nodules are found in general in routine clinical practice, most of the time during physical examination, but also fortuitously, during different imaging procedures. Because they have malignant potential, a rigorous evaluation must be done [1]. Up to $7 \%$ of the world population has thyroid nodules, but the majority of patients $(80 \%)$ have benign lesions, such as colloid cysts and thyroiditis. Five percent of the patients are diagnosed with malignant tumors of the thyroid gland that are described in almost all the cases as primary and epithelial [2].

Vascular thyroid lesions represent a disputed subject in thyroid pathology for many years [3]. The two main categories are the benign neoformation lesions, such as hemangiomas, and malignant tumors, like angiosarcoma (AS) and angiosarcomatoid carcinoma [2]. AS of the thyroid gland is a rare malignant tumor of endothelial differentiation, which has its highest incidence in the European Alpine mountains and specific in Switzerland,
Austria and Northern Italy [4], where they can account for up to $16 \%$ of all malignant thyroid tumors. The high incidence in this region is considered to be due to the lack of iodine, which leads to chronic multinodular goiter and hemorrhagic nodules [5].

Most commonly, the thyroid AS affects female patients, being reported in advanced ages (median age 65 years) [2]. It arises from the vascular parts of the thyroid gland, being histopathologically defined by the unusual endothelial differentiation [6]. This can be highlighted by the expression of vascular markers - cluster of differentiation 31 (CD31), cluster of differentiation 34 (CD34) and factor VIII (FVIII)related antigen. CD31 is by far the most the most sensitive and specific marker [4]. The vascular canals are revealed at the microscopic examination [6].

This particular type of thyroid tumor is very aggressive. Its systemic metastases appear in a short period of time, especially at lymph nodes, lung, skin and bones [7]. The optimal treatment consists in a very wide surgical excision,

This is an open-access article distributed under the terms of a Creative Commons Attribution-NonCommercial-ShareAlike 4.0 International Public License, which permits unrestricted use, adaptation, distribution and reproduction in any medium, non-commercially, provided the new creations are licensed under identical terms as the original work and the original work is properly cited. 
if the tumor is removable. Adjuvant chemoradiotherapy may be effective as further therapeutic option [6]. The prognosis is very poor, most of the patients die within six months after diagnosis [7].

Due to the rarity of this tumor, a standardized protocol of treatment is not available. A review published in 2013 by Kaur et al. identified a number of only 48 published cases of thyroid AS [8], while five years later, in 2018, another review published by De Felice et al. identified 61 patients [9]. So, only 13 new patients were identified in five years. The results of the reviews lacked statistical significance regarding the best therapeutic management although they concluded that surgical resection should be the gold standard. These patients should be referred to a specialized center in the treatment of sarcomas to ensure the optimal results $[8,9]$.

Out of 452 excised thyroid samples that were assessed over a period of almost five years (between January 2015 and September 2019) at the Department of General Surgery, Prof. Dr. Agrippa Ionescu Clinical Emergency Hospital, Bucharest, Romania, only one case of AS was encountered.

\section{Aim}

The current study reports a case of thyroid AS, being add, in this way, to the available literature of rare and atypical subtype of sarcomas.

\section{Case presentation}

A 76-year-old male patient presented to the Department of Endocrinology, Prof. Dr. Agrippa Ionescu Clinical Emergency Hospital, complaining of dyspnea, dysphonia and asthenia. Thyroid gland high-resolution ultrasonography showed an enlargement of the right lobe and the presence of a nodular lesion. In contrast, the left lobe was of normal size and normal structure. Family history was negative regarding malignancies and thyroid disease.

The thyroid function was evaluated by measuring serum levels of free triiodothyronine (FT3), free thyroxine (FT4), and thyroid-stimulating hormone (TSH, thyrotropin). The results of thyroid function tests were within the normal range.

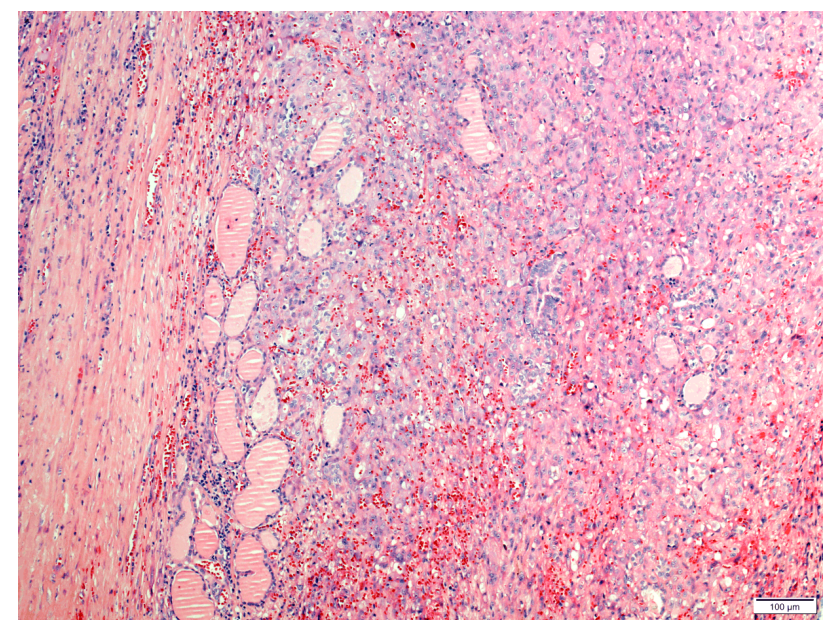

Figure 1 - Hematoxylin-Eosin (HE) staining $(\times 100)$ shows the histological features of angiosarcoma, with normal tissue of the thyroid gland in the peripheral edge and areas with large epithelioid cells.
The patient was a heavy smoker, with arterial hypertension, atrial fibrillation and type 2 diabetes mellitus. At that time, blood test results revealed a serum creatinine of $2.3 \mathrm{mg} / \mathrm{dL}$, serum hemoglobin $(\mathrm{Hb}) 10.1 \mathrm{~g} / \mathrm{dL}$, iron $21 \mu \mathrm{g} / \mathrm{dL}$, white blood cells $12100 / \mu \mathrm{L}$ with $72.6 \%$ neutrophils.

The patient was transferred to the Department of General Surgery.

The fine-needle aspiration (FNA) was performed, but it was not significant. The cytology result pointed "suspicious for malignancy". Before biopsy, a local ethical agreement and informed consent of the patient were obtained.

Surgical management was decided after iron supplementation and normalization of the serum $\mathrm{Hb}$ value. The intraoperative examination revealed a large nodule of the right lobe, with the invasion of the infrahyoid muscles. Enlarged local adenopathies were not identified at exploration. The capsule of the tumor was extremely friable and bled easily at dissection. A total thyroidectomy was performed, with the excision of the affected muscles. The tissue fragment was sent to Department of Pathology for the ultimate diagnosis.

The right thyroid lobe measured $82 / 60 / 40 \mathrm{~mm}$, presenting an encapsulated nodule. It was firm and yellow-grey, measuring $38 / 36 \mathrm{~mm}$, being identified by hemorrhagic areas in the central part, but also by the large necrotic tissue areas (almost 40\%).

The histopathological (HP) assessment showed malignant proliferation characterized by epithelioid, large rounded cells with relatively high nuclear grade (Figure 1). The cells had abundant eosinophilic cytoplasm and prominent nucleoli. Atypical mitoses were present (Figure 2). Moreover, the cells grow in sheets and lined abnormal vascular spaces that contained erythrocytes (Figures 3 and 4). There were areas of necrosis, hemorrhage, sclerosis and calcification.

Regarding the immunohistochemical profile, the neoplastic cells were strongly positive for CD31 (Figure 5), erythroblast transformation-specific related gene (ERG) (Figure 6) and CD34. The cytoplasm of epithelioid cells was intense positive for FVIII-related antigen. Epithelial differentiation markers, such as cytokeratin, thyroid transcription factor-1 (TTF-1), thyroglobulin and epithelial membrane antigen (EMA) were negative.

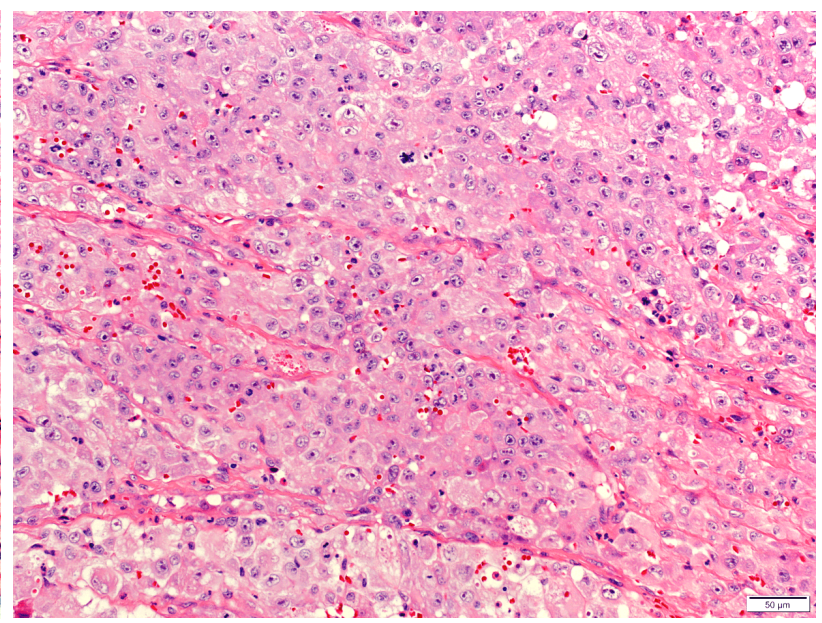

Figure $2-H E$ staining $(\times 200)$ highlights tumor cells with eosinophilic cytoplasm and large, vesicular nuclei with prominent nucleoli. Numerous atypical mitoses are present. 


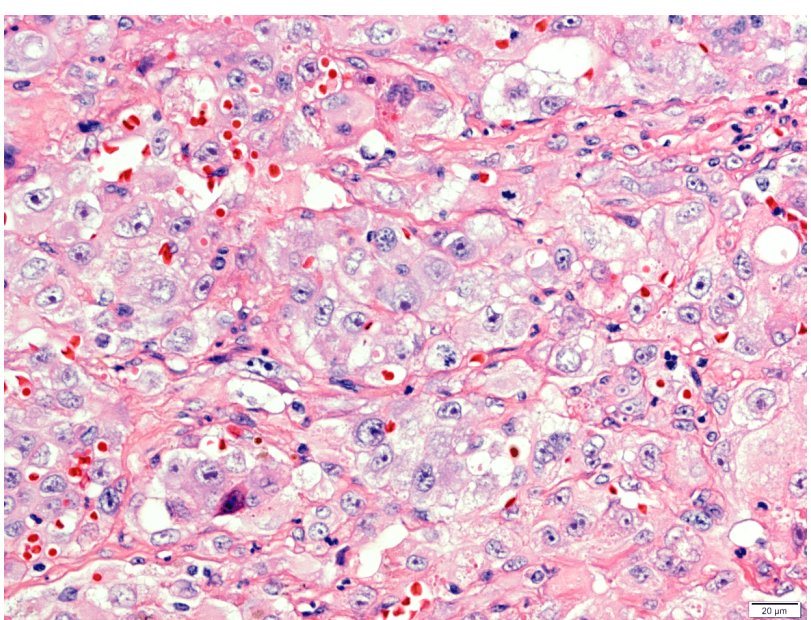

Figure $3-H E$ staining $(\times 400)$ shows numerous vascular channels bordered by the epithelioid cells.

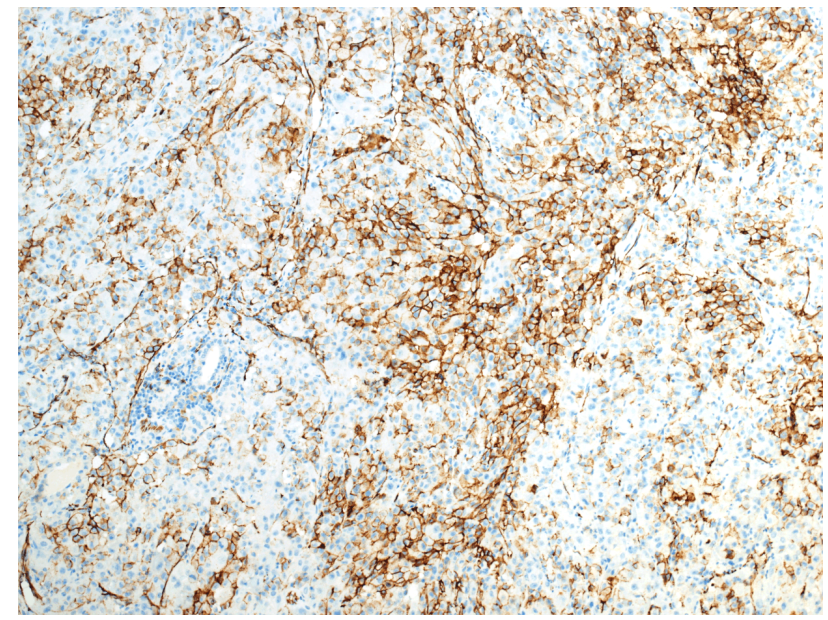

Figure 5 - Immunohistochemical staining $(\times 100)$ shows strong diffuse immunoreactivity for anti-CD31 antibody. CD31: Cluster of differentiation 31.

The final histological report was primary epithelioid AS of the thyroid, grade 3 according to Fédération Nationale des Centres de Lutte Contre le Cancer (FNCLCC).

Postoperatively, the patient presented a wound dehiscence that was treated with special dressings. The evolution was favorable. Total body computed tomography was performed after surgical intervention and no metastatic lesions were detected. The patient fully recovered after seven days of hospitalization and left the Department in a good clinical condition. He received hormonal substitution therapy.

\section{ㅁ Discussions}

AS is a rare and highly aggressive mesenchymal tumor [6]. The main predisposing factors are the chronic lymphedema and radiation exposure. Most commonly, it has been described on the skin and superficial soft tissues. However, lesions of the heart, breast, liver, bone and spleen were encountered. ASs are characterized by locoregional recurrence, nodal and distant metastases, having poor prognoses $[10,11]$.

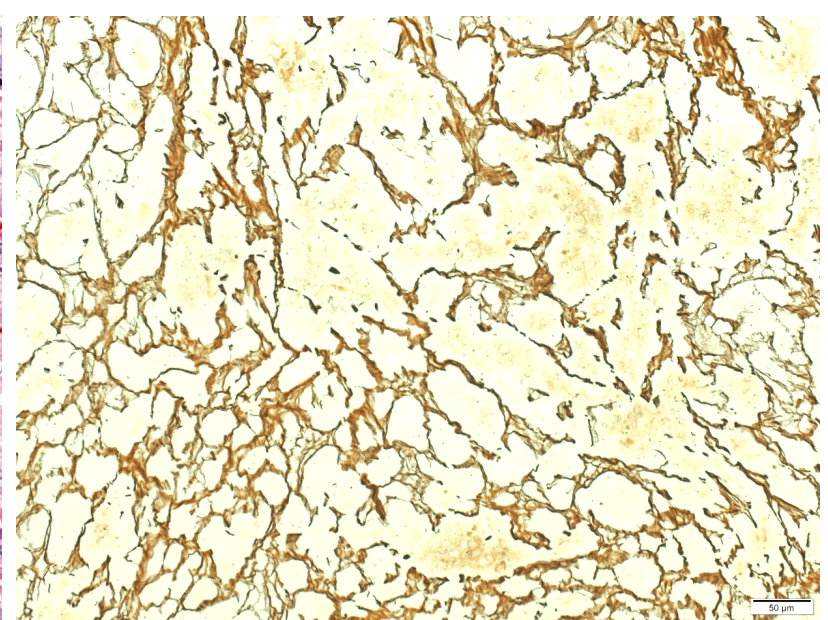

Figure 4 -Silver staining $(\times 200)$ shows the vasoformation architecture.

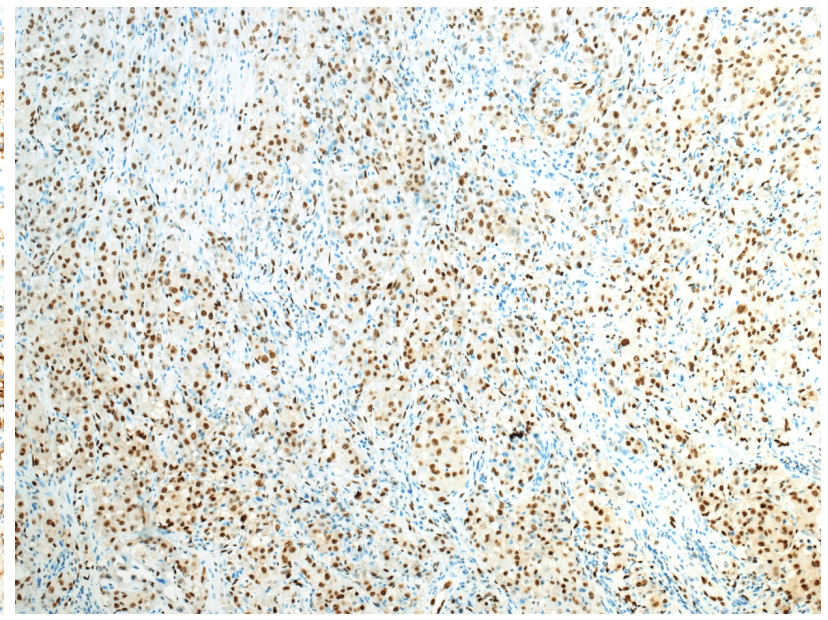

Figure 6 - Immunohistochemical staining $(\times 100)$ shows strong immunoreactivity for anti-ERG antibody. ERG: Erythroblast transformation-specific related gene.

We reported the case of a male patient, from a nonAlpine region (Bucharest, Romania), diagnosed with AS of the thyroid gland.

This kind of tumor can develop on a substrate of chronic thyroid affection, such as multinodular goiter [2] Iodine deficiency is the main cause for endemic thyroid goiter [12]. This was not the case of our patient because in Romania all salts commercialized are supplemented with iodine, a fact required by the law.

FNA biopsy is considered to be the main diagnostic tool for thyroid nodules, being an important factor in deciding the surgical strategy [13]. However, for our patient, its result was not significant. The general surgeon performed the total thyroidectomy. Although there is not a standard surgical treatment for these tumors, one must respect the oncological principles of surgery. Therefore, wide local excision of the lesion represents the "gold standard". Primary the surgical intervention the patient was seen to the diabetologist, because of his comorbidities. A nutrition plan was established to prevent the evolution of the disease [14]. He had an early stage of diabetic nephropathy, caused by the advanced age, high levels of arterial pressure and smoking [15]. 
Postoperatively, our patient presented a wound dehiscence. Silver dressings were used to accelerate the healing [16]. Nowadays, there are many types of modern wound dressings that reduce pain and promote healing [17].

The HP examination validates the diagnosis. Most commonly, epithelioid AS affects the deep soft tissues of the extremities, thyroid gland being involved extremely rare. It is described by large, pleomorphic epithelioid cells, arranged in sheets, cellular islands or cords [18], with eosinophilic cytoplasm, central nuclei and prominent nucleoli [19]. Because the nucleus has the chromatin in the peripheral part, its aspect is vesicular. Sporadic, cells with intracytoplasmic lumina containing erythrocytes can be seen. Papillary appearance can be designed by the cellular stratification, in the malignant vascular areas. The vasoformative lesions are undoubtedly signaled by reticulin staining [18]. All over the tumor, there are highlighted increased mitotic activity, varying degrees of hemorrhage and necrosis, but also anastomosing vascular channels [19]. The histological features of the epithelioid AS define easily a clear diagnosis on routine HematoxylinEosin (HE) staining [18].

Tumor cells stains positively for anti-CD31 antibody [platelet endothelial cell adhesion molecule-1 (PECAM-1], which is a sensitive marker that characterizes all the cases of epithelioid AS [20]. CD31 expression has become known as the "gold standard" for endothelial differentiation in ASs. CD34 is a marker of vascular endothelial progenitor cells, but it is not specific [21]. Nowadays, it is demonstrated the importance of ERG, another sensitive marker of endothelial differentiation, expressed in vascular tumors [22]. Moreover, the tumor immunostainings for FVIIIrelated antigen [2]. Carcinomas do not stain for endothelial markers - FVIII, CD31 and CD34 [18].

The diagnosis is indicated also by the immunonegativity for thyroglobulin [4].

The thyroid AS can invade rapidly the cervical lymph nodes, producing early metastasis to the lung, brain, duodenum and small bowel [23].

Because there is not a validated therapeutic management after the surgical intervention, adjuvant or neoadjuvant chemotherapy with or without local radiotherapy may increase the overall survival. New treatment solutions are under investigation, involving the vascular endothelial growth factor and its receptor, but also tyrosine kinase inhibitors [7].

\section{a Conclusions}

Angiosarcoma of the thyroid gland is a rare, aggressive vascular tumor characterized by sheets of epithelioid endothelial cells. CD31 and ERG immunohistochemistry are identified to be valuable in the differential diagnosis. Having a poor prognosis, a multidisciplinary collaboration would be a more feasible approach.

\section{Conflict of interests}

None to declare. All authors participated in the case of the patient, documentation, writing and corrections of the article.

\section{Authors' contribution}

Adrian Daniel Tulin, Adelaida Avino, Laura Răducu, Maria Daniela Tănăsescu and Dorin Ionescu are main authors.

\section{Special thanks}

Thanks for your contribution Florin Obrocea, MD and Elena Cristina Tianu, MD.

\section{References}

[1] Popoveniuc G, Jonklaas J. Thyroid nodules. Med Clin North Am, 2012, 96(2):329-349. https://doi.org/10.1016/j.mcna. 2012.02.002 PMID: 22443979 PMCID: PMC3575959

[2] Petronella P, Scorzelli M, Luise R, lannaci G, Sapere $P$, Ferretti M, Costanzo RMA, Freda F, Canonico S, Rossiello R. Primary thyroid angiosarcoma: an unusual localization. World $\mathrm{J}$ Surg Oncol, 2012, 10:73. https://doi.org/10.1186/1477-7819 -10-73 PMID: 22553943 PMCID: PMC3490834

[3] Altinay S, Ozen A, Namal E, Ertürküner P. Electron microscopic analysis of an angiosarcoma of the thyroid from a non-Alpine endemic goiter region: a case report and brief review of the literature. Oncol Lett, 2014, 8(5):2117-2121. https://doi.org/10.3892/ol.2014.2470 PMID: 25289092 PMCID: PMC4186527

[4] Couto J, Martins RG, Santos AP, Matos J, Torres I. Invasive thyroid angiosarcoma with a favorable outcome. Int J Endocrinol Metab, 2014, 12(4):e15806. https://doi.org/10.5812/ijem. 15806 PMID: 25745482 PMCID: PMC4338647

[5] McCabe P, Bishop JW, Semrad TJ. Non-Alpine thyroid angiosarcoma after radiation exposure: a case report. AACE Clin Case Rep, 2017, 3(3):e205-e209. https://doi.org/10.4158/EP 161423.CR

[6] Bayır Ö, Yılmazer D, Ersoy R, Akca Y, Saylam G, Han Ü, Özdek A, Çakır B, Korkmaz MH. An extremely rare case of thyroid malignancy from the non-Alpine region: angiosarcoma. Int J Surg Case Rep, 2016, 19:92-96. https://doi.org/10. 1016/j.jjscr.2015.12.028 PMID: 26741273 PMCID: PMC 4756211

[7] Marina M, Corcione L, Serra MF, Ferri T, Silini EM, Ceresini G. Primary epithelioid angiosarcoma of the thyroid in a patient occupationally exposed to radiations. Front Endocrinol (Lausanne), 2018, 9:577. https://doi.org/10.3389/fendo.2018.00577 PMID: 30327639 PMCID: PMC6174197

[8] Kaur A, Didolkar MS, Thomas A. Angiosarcoma of the thyroid: a case report with review of the literature. Endocr Pathol, 2013, 24(3):156-161. https://doi.org/10.1007/s12022-013-92 53-z PMID: 23794134

[9] De Felice F, Moscatelli E, Orelli S, Bulzonetti N, Musio D, Tombolini V. Primary thyroid angiosarcoma: a systematic review. Oral Oncol, 2018, 82:48-52. https://doi.org/10.1016/ j.oraloncology.2018.05.004 PMID: 29909901

[10] Fayette J, Martin E, Piperno-Neumann S, Le Cesne A, Robert $C$, Bonvalot $S$, Ranchère $D$, Pouillart $P$, Coindre JM, Blay JY. Angiosarcomas, a heterogeneous group of sarcomas with specific behavior depending on primary site: a retrospective study of 161 cases. Ann Oncol, 2007, 18(12):2030-2036. https://doi.org/10.1093/annonc/mdm381 PMID: 17974557

[11] Buehler D, Rice SR, Moody JS, Rush P, Hafez GR, Attia S, Longley BJ, Kozak KR. Angiosarcoma outcomes and prognostic factors: a 25-year single institution experience. Am J Clin Oncol, 2014, 37(5):473-479. https://doi.org/10.1097/COC.0b 013e31827e4e7b PMID: 23428947 PMCID: PMC3664266

[12] Asmelash D, Tesfa K, Biadgo B. Thyroid dysfunction and cytological patterns among patients requested for thyroid function test in an endemic goiter area of Gondar, North West Ethiopia. Int J Endocrinol, 2019, 2019:9106767. https://doi.org/ 10.1155/2019/9106767 PMID: 31511773 PMCID: PMC 6710807

[13] Feldkamp J, Führer D, Luster M, Musholt TJ, Spitzweg C Schott M. Fine needle aspiration in the investigation of thyroid nodules. Dtsch Arztebl Int, 2016, 113(20):353-359. https:// doi.org/10.3238/arztebl.2016.0353 PMID: 27294815 PMCID: PMC4906830

[14] Balan DG, Balcangiu Stroescu AE, Tanasescu MD, Diaconescu A Raducu L, Mihai A, Tanase M, Stanescu II, Ionescu D. Nutritional 
intervention in patients with diabetic renal disease. A brief presentation. Rev Chim (Bucharest), 2018, 69(11):31783182. https://doi.org/10.37358/RC.18.11.6706

[15] Balcangiu Stroescu AE, Tanasescu MD, Diaconescu A, Raducu L, Balan DG, Mihai A, Tanase M, Stanescu II, lonescu D. Diabetic nephropathy: a concise assessment of the causes, risk factors and implications in diabetic patients. Rev Chim (Bucharest), 2018, 69(11):3118-3121. https://doi.org/ 10.37358/RC.18.11.6695

[16] Avino A, Jecan CR, Cozma CN, Balcangiu Stroescu AE, Balan DG, lonescu D, Mihai A, Tanase M, Raducu L. Negative pressure wound therapy using polyurethane foam in a patient with necrotizing fasciitis. Mater Plast, 2018, 55(4):603-605. https://doi.org/10.37358/MP.18.4.5083

[17] Raducu L, Cozma CN, Balcangiu Stroescu AE, Avino A, Tanasescu MD, Balan DG, Jecan CR. Our experience in chronic wounds care with polyurethane foam. Rev Chim (Bucharest), 2018, 69(3):585-586. https://doi.org/10.37358/ RC.18.3.6154

[18] Hart J, Mandavilli S. Epithelioid angiosarcoma: a brief diagnostic review and differential diagnosis. Arch Pathol Lab Med, 2011, 135(2):268-272. https://doi.org/10.1043/1543-2165-135.2.268 PMID: 21284449
[19] Yang F, Yang Y, Yu J, Zheng J, Zhu Y, Shao D, Chen D, Wang S. Primary epithelioid angiosarcoma of the adrenal gland: aggressive histological features and clinical behavior. Int $J$ Clin Exp Pathol, 2018, 11(5):2721-2727. PMID: 31938388 PMCID: PMC6958267

[20] Wang L, Lao IW, Yu L, Wang J. Clinicopathological features and prognostic factors in angiosarcoma: a retrospective analysis of 200 patients from a single Chinese Medical Institute. Oncol Lett, 2017, 14(5):5370-5378. https://doi.org/10.3892/ ol.2017.6892 PMID: 29113171 PMCID: PMC5656021

[21] Sullivan HC, Edgar MA, Cohen C, Kovach CK, HooKim K, Reid MD. The utility of ERG, CD31 and CD34 in the cytological diagnosis of angiosarcoma: an analysis of 25 cases. J Clin Pathol, 2014, 68(1):44-50. https://doi.org/10.1136/jclin path-2014-202629 PMID: 25352641

[22] Miettinen M, Wang Z, Sarlomo-Rikala M, Abdullaev Z, Pack SD, Fetsch JF. ERG expression in epithelioid sarcoma: a diagnostic pitfall. Am J Surg Pathol, 2013, 37(10):1580-1585. https:// doi.org/10.1097/PAS.0b013e31828de23a PMID: 23774169 PMCID: PMC3772974

[23] Innaro N, Succurro E, Tomaino G, Arturi F. Nonalpine thyroid angiosarcoma in a patient with Hashimoto thyroiditis. Case Rep Oncol Med, 2013, 2013:901246. https://doi.org/10.1155/ 2013/901246 PMID: 24349811 PMCID: PMC3855954

\section{Corresponding authors}

Laura Răducu, Lecturer, MD, PhD, Department of Plastic and Reconstructive Surgery, Prof. Dr. Agrippa lonescu Clinical Emergency Hospital, 7 Architect lon Mincu Street, Sector 1, 011356 Bucharest, Romania; Phone +40723511 985, e-mail: raducu.laura@yahoo.com

Maria Daniela Tănăsescu, Assistant Professor, MD, PhD, Discipline of Internal Medicine I and Nephrology, Department of Medical Semiology, Faculty of Medicine, Carol Davila University of Medicine and Pharmacy, Bucharest; Department of Nephrology, Emergency University Hospital Bucharest, 169 Splaiul Independenţei Avenue, Sector 5, 050098 Bucharest, Romania; Phone +40745-042 785, e-mail: tanasescu2007@yahoo.com 